\title{
A armadilha da baixa complexidade em Minas Gerais: o desafio da sofisticação econômica em um estado exportador de commodities
}

Fernanda Cimini Salles*

Elisa Pinto Rocha**

Ivana Villefort de Bessa Porto ${ }^{* * *}$

Felipe Lopes Vieira Vasconcelos****

\section{RESUMO}

Minas Gerais convive, há décadas, com o desafio da sofisticação econômica. Na tentativa de construir caminhos para a transformação de sua economia, o governo de Minas Gerais lançou a plataforma Dataviva, possibilitando a aplicação da abordagem da complexidade econômica no âmbito de políticas públicas de desenvolvimento. $\mathrm{O}$ artigo visa contribuir para essa reflexão, por meio da análise da complexidade econômica dos estados brasileiros no período entre 2002 e 2014, com foco em Minas Gerais. A pesquisa revela que a economia mineira está presa em uma "armadilha de baixa complexidade", o que demanda uma intensa colaboração entre os setores público e privado para a descoberta e investimento em atividades que contribuam para a sofisticação econômica.

\footnotetext{
* Universidade Federal de Minas Gerais (UFMG), Belo Horizonte (MG), Brasil. E-mail: fcimini@cedeplar.ufmg.br.

** Fundação João Pinheiro (FJP), Belo Horizonte (MG), Brasil. E-mail: elisa.rocha@fjp.mg.gov.br.

*** Universidade Federal de Minas Gerais (UFMG), Belo Horizonte (MG), Brasil. E-mail: ivanavillefort@gmail.com.

**** Governo de Minas Gerais, Belo Horizonte (MG), Brasil. E-mail: felipevv@gmail.com.
} 
Palavras-Chave | Complexidade Econômica; Inovação; Políticas Públicas; Commodities; Dataviva

Códigos-JEL | O14; O18

\section{The low complexity trap in Minas Gerais:}

\section{the challenge of economic sofistication in a commodity exporter state}

\section{ABSTRACT}

Minas Gerais has dealt for decades with the challenge of economic sophistication. In an attempt to build paths for its economy's transformation, the Government of Minas Gerais launched the Dataviva platform, allowing economic complexity's approach to be used in the context of public development policies. This article aims to contribute to this debate by analyzing the economic complexity of the Brazilian states from 2002 to 2014, focusing on Minas Gerais. The research reveals that Minas' economy is stuck in a "low complexity trap", which requires a close collaboration between the public and private sectors for the discovery and investment in activities that contribute to economic sophistication.

KeY-Words | Economic Complexity; Innovation; Public Policies; Commodities; Dataviva JEL CODES | O14; O18 


\section{Introdução}

A história da economia mineira é uma história de busca continuada pela sofisticação econômica. Durante praticamente todo o século XX, Minas Gerais manteve-se em posição desvantajosa em relação aos demais estados brasileiros, tendo dificuldade para acompanhar o ritmo de crescimento industrial, financeiro e comercial dos estados de São Paulo e Rio de Janeiro (BDMG, 2002). Com vocação natural para mineração e metalurgia, a economia mineira desempenhou, por muitas décadas, papel secundário no centro dinâmico do país (BDMG, 1968, 1989, 2002).

Os anos 2000 pareciam apontar para uma reversão dessa história. A expansão da demanda mundial por minério e o significativo aumento dos preços destes produtos no mercado internacional conferiram a Minas Gerais posição de destaque no contexto nacional. O novo ciclo de crescimento, impulsionado pelas exportaçóes, foi acompanhado pela expansão e atração de novos investimentos, contribuindo positivamente para o crescimento do emprego, da geração de renda e da arrecadação para os cofres estaduais e municipais. ${ }^{1}$ Contudo, bastou esse ciclo apontar sinais de esgotamento para a economia mineira voltar a conviver com estagnação econômica e contenção do gasto público. ${ }^{2}$

A dificuldade de manter trajetória estável de crescimento é apenas um dos efeitos perversos decorrentes da especialização produtiva em recursos naturais. Há décadas, a literatura econômica discute se a maior concentração da estrutura produtiva na extração de recursos naturais seria uma "maldição" para as economias que se especializam nesses setores, por impedir o desenvolvimento de indústrias dinâmicas (PREBISCH, 1949; CORDEN, 1984; SACHS; WARNER, 1995; PALMA, 2005). Esse argumento, conhecido sob o rótulo de "doença holandesa", ${ }^{3}$ voltou a ganhar fôlego após o ciclo recente de boom das commodities e vários autores têm chamado a atenção para os múltiplos efeitos deletérios da abundância em recursos naturais (BRESSER-PEREIRA; GALA, 2010; NU CEPAL, 2013; MEDEIROS, 2012; CAMARGO; GALA, 2017). Ainda que a literatura tenha avançado na compreensão dos mecanismos associados às externalidades negativas dos recursos naturais, o maior desafio desse debate é definir, empiricamente, sob quais aspectos um ciclo

1 Para uma análise dos efeitos econômicos do boom em Minas Gerais, ver Campolina e Cavalcante (2017).

2 Desde 2013, em função da redução do preço do minério de ferro, a arrecadação dos impostos associados à atividade minerária, como a Compensação Financeira pela Exploração de Recursos Minerais (CFEM), tem apresentado trajetória de queda.

3 O termo doença holandesa refere-se aos efeitos adversos da descoberta de gás natural, na década de 1960, e à subsequente apreciação do câmbio holandês, prejudicando o setor industrial (CORDEN, 1984). Desde então, o termo tem sido utilizado para descrever períodos de elevação de preço de commodities associados à desindustrialização. 
de boom de commodities pode ser considerado uma doença para o desenvolvimento futuro da região.

Em trabalho recente, Camargo e Gala (2017) lançaram novo olhar sobre esse debate, ao se basearem no Atlas da complexidade econômica, proposto por Hausmann et al. (2014), para analisar o impacto da concentração das exportaçôes em recursos naturais na evolução da complexidade dos países, no período de 1963 a 2013. Os resultados corroboram a visão de que a concentração das exportações em produtos de baixa complexidade, efeito associado à doença holandesa, comprometem o desenvolvimento de indústrias dinâmicas. Os autores observaram que o aumento de concentração das exportações em produtos como petróleo, minério de ferro ou soja leva à perda de complexidade econômica futura, comprometendo o desenvolvimento das regiôes que se especializam na produção desses produtos. ${ }^{4}$

À luz da trajetória vivenciada por Minas Gerais, o presente artigo contribui para o debate sobre os efeitos da concentração das exportaçôes em recursos naturais. Assim como no trabalho de Camargo e Gala (2017), esse estudo baseia-se na abordagem do Atlas da complexidade econômica para analisar o efeito do aumento das exportações de recursos naturais na sofisticação da economia mineira. Para tanto, é analisado o comportamento de indicadores de complexidade econômica, no período entre 2002 a 2014, disponíveis na plataforma Dataviva, ${ }^{5}$ ferramenta que permite a análise de complexidade econômica para os estados brasileiros.

O principal achado da pesquisa é que a economia de Minas Gerais encontra-se presa em uma armadilha de baixa complexidade econômica: a estrutura produtiva existente enfraquece as bases econômicas necessárias para o desenvolvimento das capacidades requeridas para a sofisticação futura. Esse resultado foi confirmado a partir da análise dos indicadores de complexidade econômica, prognóstico de complexidade e complexidade dos produtos exportados por Minas Gerais. A análise apresentada sugere que a superação dessa armadilha será mais difícil para Minas Gerais do que para os outros estados brasileiros que possuem níveis similares de desenvolvimento econômico. Dessa forma, o artigo oferece uma releitura do histórico desafio enfrentado por Minas Gerais, ao mesmo tempo que sinaliza para efeito perverso do boom das commodities no prognóstico de sofisticação do estado.

\footnotetext{
4 Nos países em que a exportação desses produtos representa cerca de $50 \%$ da pauta exportadora, a perda de complexidade é ainda mais acentuada, com um coeficiente de 0,242 a cada quatro anos.

5 Plataforma Dataviva: <http://dataviva.info>.
} 
A seguir, é feita uma revisão da abordagem da complexidade econômica, discutindo suas principais premissas e argumentos. Posteriormente apresenta-se o tratamento metodológico realizado na análise, com destaque para os indicadores propostos originalmente pelo Atlas da complexidade econômica e os indicadores oferecidos pela plataforma Dataviva. São discutidos os resultados para o período 2002-2014, realizando-se uma análise comparativa entre os estados brasileiros, bem como da complexidade econômica de Minas Gerais. Por fim, a conclusão sintetiza o argumento, apontando seus limites, e oferece uma reflexão sobre os caminhos para a superação da armadilha da baixa complexidade econômica.

\section{Abordagem teórica}

A tese de que a sofisticação da estrutura produtiva é central para a superação do subdesenvolvimento tem ganhado espaço na literatura econômica recente. Os trabalhos de Hidalgo et al. (2007) sobre complexidade econômica reacenderam o debate sobre a importância da transformação estrutural para o processo de desenvolvimento econômico, trazendo novos insights para a tradição estruturalista (BRESSER-PEREIRA, 2016; GALA et al., 2016). Em contraponto à visão neoclássica que, em geral, desconsidera a importância de diferenças setoriais, a visão estruturalista propõe que o processo de desenvolvimento econômico está associado à reorientação da produção de setores de baixa produtividade para setores dinâmicos, com retornos crescentes de escala (PREBISCH, 1949; FURTADO, 1961; KALDOR, 1966).

A teoria da complexidade econômica conecta-se ao argumento estruturalista ao sugerir que a especialização na produção de determinados produtos traz diferentes implicaçōes em termos de performance econômica (HAUSMANN; HWANG; RODRIK, 2007). O modelo proposto por Hidalgo e Hausmann (2009) incorpora o comércio internacional por entender que as vantagens comparativas das naçōes são reveladoras do grau de especialização econômica. Nessa perspectiva, a mudança estrutural deve ser orientada pelo aumento da participação de produtos sofisticados (embarcados com tecnologia e serviços avançados) no total produzido e exportado pelos países.

A novidade dessa abordagem é o método proposto pelos autores para estimar a complexidade dos produtos a partir de sua comercialização internacional. Em vez de utilizar classificações ad hoc de intensidade tecnológica ou indicadores baseados na renda dos países que exportam determinado produto, Hidalgo e Hausmann (2009) propõem uma medida reflexiva que conecta países e produtos exportados com vantagem comparativa revelada. 
Como em um jogo de lego, cada país seria equivalente a uma cesta de peças e cada produto seria uma combinação possível das peças. Produtos complexos seriam equivalentes a um modelo de lego composto por peças diversas, mas ao mesmo tempo exclusivas, não disponíveis nos demais modelos. As peças seriam o equivalente às capacidades produtivas disponíveis em cada localidade. Regiōes capazes de produzir produtos complexos seriam dotadas de capacidades complexas. A intuição do modelo é de que se uma localidade consegue exportar um determinado produto com vantagem comparativa, essa localidade possui as capacidades necessárias para sua produção. Nesse sentido, a complexidade da localidade está relacionada à complexidade dos produtos exportados por ela.

Nessa perspectiva, produtos complexos são resultado da combinação de capacidades diversas e exclusivas. A diversidade é mensurada pelo número de produtos exportados por um país (quanto mais produtos, maior a diversidade de capacidades disponíveis) e a exclusividade é medida pelo número de países que exportam o mesmo produto (quanto menor o número de países, mais exclusivas são as capacidades disponíveis). A complexidade do produto é então obtida por meio da interação entre ambas as medidas - diversidade e exclusividade. Já a complexidade de uma localidade é mensurada a partir da participação de produtos complexos na cesta de exportação. Com isso, o modelo permite mensurar a disponibilidade de capacidades em uma localidade sem fazer qualquer tipo de premissa sobre a natureza dessas capacidades, olhando apenas para a diversidade e exclusividade dos produtos exportados.

Ao comparar os indicadores de complexidade econômica entre os países, Hausmann et al. (2014) encontraram uma forte correlação entre complexidade e desenvolvimento: nos países que apresentam baixa dependência de commodities naturais (menor que $10 \%$ da pauta), ${ }^{6}$ os indicadores de complexidade econômica respondem por $75 \%$ da variação em renda per capita. A relação entre complexidade econômica e desenvolvimento de uma região não se limita à renda per capita. Segundo Hausmann et al. (2014), em países nos quais o nível de complexidade econômica mostra-se mais elevado do que o esperado, dado o seu nível de renda, o crescimento econômico tende a ser mais rápido. Hartmann et al (2017) encontraram evidências adicionais para reforçar a importância da complexidade econômica para o desenvolvimento: segundo os autores, países que exportam produtos mais complexos tendem a ser mais igualitários do que países com baixa complexidade econômica.

6 Como observa Hausmann et al. (2014), localidades abundantes em recursos naturais podem ser relativamente ricas sem serem complexas. 
Assim, a complexidade econômica de determinada localidade funciona como um importante indicativo de transformações estruturais futuras, impactando na capacidade de geração e redistribuição de renda. Por isso, a problemática central que perpassa a teoria da complexidade econômica é entender os condicionantes do processo de sofisticação econômica. Para tanto, a teoria busca estimar a probabilidade de sofisticação futura a partir da estrutura produtiva atual. Isso é possível uma vez que a probabilidade de determinada localidade desenvolver capacidades para produzir competitivamente um produto complexo está relacionada ao estoque de capacidades já existente para a produção de produtos similares, por se tratar de um processo acumulativo.

A história traz evidências de que o ganho de complexidade se dá por meio de uma trajetória cumulativa de construção de capacidades. Em economias avançadas, o desenvolvimento de capacidades foi iniciado concomitantemente com o processo de industrialização. Aqueles países que historicamente iniciaram mais cedo tiveram como vantagem a acumulação e a expansão gradual do conhecimento produtivo. Como consequência, foi mais fácil para esses países produzir e exportar produtos complexos, já que eles detinham um montante substantivo de conhecimento produtivo acumulado. Em contraste, nos países cujo processo de industrialização deu-se tardiamente, o esforço de construção e acúmulo de capacidades mostrou-se bem mais dramático. Além da necessidade de construírem capacidades para percorrer o caminho da industrialização, os países de industrialização tardia ainda precisaram enfrentar a intensa competição internacional com aqueles que já dispunham de um estoque maior de capacidades. Não é de se espantar que a grande maioria falhou no processo de catch-up.

Nesse aspecto, a teoria da complexidade também oferece novo olhar sobre as trajetórias de acúmulo de capacidades e de evolução da especialização da estrutura produtiva de cada país. Hausmann e Klinger (2007) e Hidalgo et al. (2007) verificaram que os países que obtiveram êxito no ganho de sofisticação econômica o fizeram a partir da produção de produtos próximos aos já exportados com vantagem comparativa. Para mensurar o grau de proximidade entre os produtos, os autores baseiam-se na metodologia de rede para estimar a probabilidade de diferentes pares de produtos serem coexportados. A intuição dos autores é de que produtos coexportados compartilham capacidades produtivas similares, guardando uma relação de proximidade. O resultado é a criação de uma rede de produtos, o product space, que informa quão conectados estão os produtos entre si e qual a posição da estrutura produtiva de uma localidade em relação ao product space. 
Ao analisar o product space, Hidalgo et al. (2007) encontraram uma estrutura na qual produtos complexos estão localizados na área mais densa da rede. Não por acaso, países desenvolvidos apresentam vantagem comparativa em produtos localizados no centro do product space, ao passo que aqueles em desenvolvimento possuem vantagem comparativa em produtos localizados na periferia. Países que conseguiram tornar suas exportações mais complexas, movendo-se para o centro do product space, obtiveram êxito na melhoria da sua renda per capita. Por isso, os autores propuseram que o processo de desenvolvimento ocorre por meio do deslocamento da estrutura produtiva na direção do centro da rede, o que implica um processo de aquisição e acúmulo de novas capacidades.

Para ilustrar esse argumento, Hausmann e Klinger (2007) utilizam a metáfora de uma floresta em que a estratégia de sobrevivência dos macacos é saltar para árvores mais próximas. De forma análoga, no processo de diversificação de seus negócios, firmas deveriam optar por saltos próximos, investindo em capacidades que sejam relacionadas às capacidades existentes. Nessa perspectiva, a estrutura do product space e as relações de proximidade existentes entre os produtos exportados com vantagem comparativa revelada por determinada localidade tornam-se elementos-chave para o sucesso da transformação estrutural. Quanto maior for o leque de capacidades produtivas compartilhadas entre as diferentes atividades econômicas ou, nos termos da teoria da complexidade econômica, quanto mais conectado for o product space, melhores serão as condições para que as firmas realizem o salto para produtos mais complexos e, mais importante, ganhem vantagem comparativa na exportação desses produtos no comércio internacional.

No entanto, nem todos os países possuem incentivo para sofisticar sua estrutura produtiva, mesmo em atividades próximas. Hausmann e Hidalgo (2011) observaram que países com baixa complexidade econômica apresentam maior dificuldade para encontrar utilidade em capacidades adicionais do que aqueles que já apresentam uma estrutura produtiva complexa, fenômeno denominado por eles como "armadilha da aquiescência":

[...] countries with few capabilities will have a lower probability of finding uses for any additional capability than countries with many capabilities as the number of potential combinations increases as a power of the number of capabilities available in a country. Hence, countries with few (many) capabilities will face low (high) incentives to the accumulation of additional capabilities. We call this the quiescence trap. (HAUSMANN; HIDALGO, 2011, p. 4) 
Segundo os autores, a armadilha da aquiescência se manifesta porque a probabilidade da adição de uma nova capacidade conectar-se às capacidades existentes e gerar novos produtos é baixa em um contexto de capacidades limitadas. Consequentemente, um país com baixa complexidade não produz produtos complexos porque não dispõe de capacidades e, por não produzir produtos complexos, não tem incentivo para adquirir novas capacidades, já que a contribuição das capacidades adicionais para a produção de novos produtos é baixa. Ademais, os autores sugerem que à medida que o progresso tecnológico avança e a produção mundial passa a demandar maior número de capacidades, a distância entre os países no product space torna-se ainda mais acentuada, agravando a armadilha da aquiescência. Assim, a armadilha da aquiescência - ou, armadilha da baixa complexidade - seria um dos principais obstáculos para o processo de sofisticação econômica dos países que se encontram na periferia do product space.

Ao sugerir que a produção mundial está conectada em rede e que essa rede apresenta uma estrutura hierárquica, demarcando posiçôes de centro e periferia, a teoria da complexidade permite o diálogo com teorias estruturalistas que já apontavam para os constrangimentos colocados pela dinâmica do comércio internacional à mudança estrutural nas economias menos desenvolvidas (PREBISCH, 1949; FURTADO, 1961; KALDOR, 1966). Até mesmo as recomendações de políticas propostas por teóricos estruturalistas e teóricos da complexidade parecem caminhar na mesma direção: desenvolvimento de indústrias modernas e construção de capacidades.

Porém, o alinhamento entre políticas para a transformação estrutural e a construção de capacidades não é nada trivial. Enquanto os estruturalistas, sobretudo cepalinos, voltam-se para as causas macroestruturais, relacionadas às disparidades tecnológicas, às restrições na balança de pagamentos e à dependência do capital externo (MISSIO; JAYME; OREIRO, 2015), os autores da teoria da complexidade econômica dão maior ênfase aos fundamentos microeconômicos, relacionados ao processo de formação de capital humano e de capacidades institucionais necessários para a transformação estrutural (HAUSMANN; HWANG; RODRIK, 2006; HAUSMANN; KLINGER, 2007). Nesse sentido, os desafios apresentados por cada uma dessas abordagens carregam implicações estratégicas distintas que, na prática, demandam um ajuste muito mais complexo do que a simples combinação de políticas (RODRIK, 2013a, 2013b).

Por exemplo, o fortalecimento gradual de capacidades sem um conjunto de políticas que promovam a industrialização dificilmente levará a uma mudança estrutural. Por outro lado, políticas de promoção da indústria avançada podem inevitavelmente 
ferir alguns fundamentos, como a proteção de direitos de propriedade intelectual e a abertura econômica. Assim, não existe uma resposta fácil para a superação da armadilha da baixa complexidade, tampouco um consenso acerca das recomendações de políticas a serem adotadas para conduzir a transformação estrutural. Experiências de diversas localidades ajudam a ilustrar as potencialidades e limites de cada política, mas o estado da arte desse debate ainda carece de soluções criativas.

\section{Metodologia}

$\mathrm{O}$ indicador sugerido pela teoria da complexidade econômica para estimar o crescimento econômico das regiôes é o índice de complexidade econômica (ECI), que seria a principal proxy do conhecimento e das capacidades produtivas disponíveis em uma localidade. Esse índice leva em conta os valores do índice de complexidade de produto $(\mathrm{PCI})^{7}$ dos produtos exportados com vantagem comparativa revelada (VCR), ponderada pelo peso desses produtos nas exportações totais da localidade. Na plataforma Dataviva, o ECI foi adaptado para os estados e municípios brasileiros, sendo calculado a partir da seguinte fórmula, desenvolvida por Freitas e Paiva (2016):

$$
E C I=\sum_{p} \frac{x_{p l}}{\sum x_{p}} V C R_{p} P C I_{p}
$$

Onde:

$x_{p l}$ representa o valor exportado do produto $p$ pela região 1 ;

$x_{p}$ representa corresponde ao valor exportado do produto $p$ pelo Brasil;

$V C R_{p}$ representa as vantagens comparativas reveladas do produto $p$ na localidade 1 , $P C I_{p}$ refere-se à complexidade do produto $p$.

Para analisar caminhos possíveis de sofisticação econômica, o product space oferece o conceito de proximidade entre produtos, desenvolvido por Hidalgo et al. (2007). A proximidade é calculada a partir da probabilidade de um par de produtos ser coexportado com vantagem comparativa revelada (VCR), conforme a seguir:

7 Importante salientar que o PCI de um determinado produto considera a interação entre diversidade e ubiquidade com base nas exportaçôes do produto no comércio mundial. Por isso, trata-se de uma medida calculada a partir dos dados de exportaçôes dos países e o seu valor independente de uma região especifica. A plataforma Dataviva disponibiliza o índice PCI de todos os produtos exportados pelo Brasil, desagregado por estados e municípios, no período 2002-2014. 


$$
\begin{aligned}
& \varphi_{k, h, t} \\
& =\min \left\{P\left(V C R_{k}>1 \mid V C R_{h}>1\right), P\left(V C R_{h}>1 \mid V C R_{k}>1\right)\right\}
\end{aligned}
$$

Produtos com alta probabilidade de coexportação podem ser considerados produtos "próximos", o que significa que eles apresentam uma forte conexão no product space e, portanto, possuem estruturas de produção que utilizam capacidades produtivas relativamente similares. Essa medida é relevante para a elaboração de inferências sobre perspectivas futuras de sofisticação econômica, pois, quanto mais próximos forem os produtos exportados por uma determinada região, maiores serão as possibilidades de otimização das capacidades produtivas existentes e de transbordamentos positivos para melhoria tecnológica. Nesse sentido, a sofisticação econômica tende a ocorrer em produtos relativamente mais próximos (JANKOWSKA; NAGENGAS; PEREA, 2012).

Agregando-se as proximidades é possível calcular a distância entre determinado produto e a estrutura produtiva existente (HAUSMANN; KLINGER, 2007). Dessa forma, a distância é a probabilidade condicional de a localidade exportar um novo produto $p$, dada sua atual estrutura de exportação. As capacidades que um país possui são capturadas pela proximidade entre os produtos que ele atualmente exporta e o produto de interesse que se quer exportar. Assim, o conceito de distância pode ser utilizado para inferir as capacidades produtivas que faltam ao país estudado a partir da proximidade entre os produtos que o país não exporta e o produto $p$.

$$
\text { distância }=\frac{\sum_{c=1}^{N}\left(1-M_{c p}\right) \varphi_{c p}}{\sum_{c=1}^{N} \varphi_{c p}}
$$

A partir dessa medida, foi possível calcular a distância média do product space dos estados brasileiros que representa o valor médio das distâncias de todos os produtos exportados por cada estado. Quanto maior for a distância média de uma região, mais disperso será o product space e, portanto, menores as possibilidades de sofisticação.

Um indicador ainda mais apurado para mensurar perspectivas futuras de sofisticação é o índice de prognóstico de complexidade (COI), construído a partir das distâncias entre os produtos que uma região está exportando com vantagem comparativa atualmente e aqueles que ela não está, ponderado pelo PCI desses produtos. Países com um elevado prognóstico de complexidade têm abundância de produtos próximos. 


$$
\text { COI }=\sum_{i} \text { densidade }_{i, c, t}\left(1-x_{i, c, t}\right) P C I_{i, t}
$$

Segundo Hausmann et al. (2014), o COI seria um adequado indicador preditivo de mudanças futuras na complexidade econômica de determinada região, podendo indicar a rapidez com que essa localidade seria capaz de adquirir novas capacidades produtivas. Cabe considerar que a plataforma Dataviva não oferece essa medida em sua base de dados. Para calculá-la foi preciso agregar os dados de densidade (medida da distância de determinada região para cada um dos produtos que ela ainda não exporta com vantagens comparativas), desenvolvidos por Hildalgo et al. (2007), e a VCR de todos os produtos não exportados por cada um dos 27 estados. Assim, os índices de ECI e COI serão utilizados como "proxy” para analisar e comparar os estados brasileiros em termos de complexidade e facilidade em adquirir novas capacidades produtivas no futuro.

\section{Análise de resultados}

Esta seção dedica-se à análise da evolução da complexidade econômica no âmbito dos estados brasileiros, no período de 2002 a 2014. O objetivo é aplicar os indicadores discutidos anteriormente - índice de complexidade econômica (ECI), índice de prognóstico de complexidade (COI), índice de complexidade de produto (PCI) e distância - para compreender as perspectivas de sofisticação da economia mineira $v i s-\grave{a}$-vis os demais estados brasileiros.

\subsection{Os estados brasileiros sob a ótica da complexidade econômica}

O ponto de partida para a análise da complexidade econômica, no âmbito subnacional, é avaliar se a relação entre o indicador de complexidade econômica e o desenvolvimento também é válida para o contexto dos estados brasileiros. Para tanto, foram utilizadas regressóes em painel com efeitos fixos para o conjunto dos 27 estados brasileiros, no período entre 2002 e 2014. Os controles utilizados foram o peso das exportações de commodities no PIB, o peso das exportações no PIB e também o tamanho do estado, mensurado por meio da população. A primeira variável controla o crescimento econômico estimulado pela exportação de commodities. A segunda captura a dependência da economia em relação ao comércio internacional. Já a terceira diz respeito ao tamanho do estado, que pode ser usada como proxy para 
o mercado doméstico. ${ }^{8}$ A Tabela 1 apresenta os resultados para as duas equaçôes, sendo a segunda com a inclusão da variável explicativa de interesse, ECI.

TABELA 1

Análise da relação entre ECI e PIB per capita para os estados

Brasil - 2002-2014

\begin{tabular}{lcc}
\hline \multirow{2}{*}{ Variáveis } & \multicolumn{2}{c}{ PIB per capita $(\mathbf{l o g})$} \\
\cline { 2 - 3 } & $(\mathbf{I})$ & $($ II) \\
\hline Participação das exportações de & $0.4331181^{* * *}$ & $0.4263653^{* * *}$ \\
commodities no PIB, log & $(0.026339)$ & $(0.0259198)$ \\
Índice de complexidade & & $0.0156511^{* * *}$ \\
econômica & & $(0.0043109)$ \\
Participação das exportações & $-5.003164^{* * *}$ & $-4.27498^{* * *}$ \\
no PIB & $(1.107658)$ & $(1.105566)$ \\
& $3.39 \mathrm{e}-07^{* * *}$ & $3.76 \mathrm{e}-07^{* * *}$ \\
Tamanho da população & $(3.49 \mathrm{e}-08)$ & $(3.57 \mathrm{e}-08)$ \\
& $-1.587054 * * *$ & $-1.748988^{* * *}$ \\
Constante & $(0.4322483)$ & $(0.426611)$ \\
\hline Observações & 351 & 351 \\
$\mathrm{R}^{2}$ & 0.7093 & 0.7208 \\
\hline
\end{tabular}

Fonte: Dataviva (exportaçôes e indicadores de complexidade); IBGE (PIB e população) Elaboração dos autores. Nota: ${ }^{* * *}$ significativo a $1 \%$.

Os erros padrôes encontram-se em parênteses.

Observa-se que o índice de complexidade econômica dos estados apresentou coeficiente positivo e estatisticamente significante para explicar as diferenças observadas no nível de renda dos estados brasileiros e a inclusão desse indicador contribuiu para um ligeiro aumento do $\mathrm{R}^{2}$, de $70 \%$ para $72 \%$.

Demonstrada essa relação, as tabelas subsequentes voltam-se para a análise do comércio exterior, já que o aumento de complexidade do estado decorre do crescimento da participação de produtos complexos na sua cesta de exportação (com VCR). Entre 2002 e 2014, todos os estados brasileiros ampliaram o valor de suas exportações (MDIC, 2016). A ampliação do valor exportado, no entanto, não foi acompanhada pelo aumento da cesta de produtos exportados com vantagem comparativa revelada: a esse respeito, como mostrado na Tabela 1, os estados brasileiros apresentaram diferentes trajetórias.

8 Esses controles também foram utilizados por Hausman et al. (2014) para sustentar o argumento de que a relação entre complexidade econômica e desenvolvimento não diz respeito ao crescimento estimulado por exportaçôes ou ao tamanho da localidade, mas sim ao estoque de conhecimento produtivo embebido nos produtos exportados. 
TABELA 2

Tamanho da cesta de produtos com vantagem comparativa revelada

Estados brasileiros - 2002-2014

\begin{tabular}{|c|c|c|c|c|c|c|c|}
\hline \multirow[t]{2}{*}{ Estados } & \multicolumn{2}{|c|}{$\begin{array}{l}\text { No de produtos com } \\
\text { VCR }>1\end{array}$} & \multirow{2}{*}{$\begin{array}{c}\text { Variação } \\
(\%)\end{array}$} & \multirow[t]{2}{*}{ Estados } & \multicolumn{2}{|c|}{$\begin{array}{l}\text { No de produtos com } \\
\text { VCR }>1\end{array}$} & \multirow{2}{*}{$\begin{array}{c}\text { Variação } \\
(\%)\end{array}$} \\
\hline & 2002 & 2014 & & & 2002 & 2014 & \\
\hline $\mathrm{AC}$ & 17 & 40 & 135,0 & $\mathrm{RN}$ & 37 & 44 & 19,0 \\
\hline $\mathrm{AM}$ & 34 & 47 & 38,0 & SE & 16 & 21 & 31,0 \\
\hline $\mathrm{AP}$ & 7 & 7 & 0,0 & DF & 20 & 13 & $-35,0$ \\
\hline PA & 36 & 36 & 0,0 & GO & 44 & 40 & $-9,0$ \\
\hline RO & 22 & 27 & 23,0 & MS & 32 & 27 & $-16,0$ \\
\hline $\mathrm{RR}$ & 17 & 12 & $-29,0$ & MT & 18 & 21 & 17,0 \\
\hline TO & 5 & 9 & 80,0 & ES & 36 & 29 & $-19,0$ \\
\hline $\mathrm{AL}$ & 9 & 11 & 22,0 & MG & 116 & 82 & $-29,0$ \\
\hline $\mathrm{BA}$ & 106 & 77 & $-27,0$ & RJ & 86 & 44 & $-49,0$ \\
\hline CE & 59 & 56 & $-5,0$ & SP & 226 & 232 & 3,0 \\
\hline MA & 13 & 14 & 8,0 & PR & 103 & 118 & 15,0 \\
\hline PB & 36 & 33 & $-8,0$ & $\mathrm{RS}$ & 128 & 142 & 11,0 \\
\hline $\mathrm{PE}$ & 70 & 49 & $-30,0$ & SC & 104 & 145 & 39,0 \\
\hline PI & 25 & 19 & $-24,0$ & Média & 53 & 52 & 6,0 \\
\hline
\end{tabular}

Fonte: Dataviva.info. Elaboração dos autores.

Os resultados indicam para Minas Gerais e outros onze estados brasileiros Roraima, Bahia, Ceará, Paraíba, Pernambuco, Piauí, Distrito Federal, Goiás, Mato Grosso do Sul, Espírito Santo e Rio de Janeiro - redução das cestas de produtos com vantagem comparativa no período de 2002 a 2014 (considerando VCR >=1). Isso significa que tais estados sofreram maior concentração de suas exportações, ao reduzirem o número de produtos exportados com vantagem comparativa revelada. Contudo, a redução da cesta de exportação com vantagem comparativa não implica necessariamente a perda de complexidade econômica, já que esse índice também leva em consideração a complexidade dos produtos que compõem a cesta.

A Tabela 3 apresenta o valor do índice de complexidade econômica para os estados brasileiros e sua variação entre 2002 e 2014. Observa-se que o Rio de Janeiro, apesar de ter aumentado a concentração de suas exportações (Tabela 2), apresentou melhoria significativa do índice de complexidade econômica, com variação positiva de $757 \%$. Minas Gerais, em contrapartida, registrou perda de complexidade durante o período analisado, com variação negativa de $96 \%$. Da mesma forma, o Estado 
de São Paulo mostrou ligeira diversificação da cesta de exportação, mas apresentou queda no indicador de complexidade. Assim, a análise da quantidade de produtos exportados com vantagem comparativa revelada não é suficiente para inferir ganhos ou perdas em termos de complexidade, pois o que importa para o processo de sofisticação é o ganho de vantagem comparativa em produtos complexos.

TABELA 3

Índice de complexidade econômica

Estados brasileiros - 2002-2014

\begin{tabular}{c|c|c|c|c|c|c|c}
\hline \multirow{2}{*}{ Estados } & \multicolumn{2}{|c|}{ ECI } & \multirow{2}{*}{$\begin{array}{c}\text { Variação } \\
\text { (\%) }\end{array}$} & \multirow{2}{*}{ Estados } & \multicolumn{2}{|c|}{ ECI } & \multirow{2}{*}{\begin{tabular}{c} 
Variaçã o \\
\cline { 5 - 6 }
\end{tabular}} \\
\cline { 2 - 3 } AC & $\mathbf{2 0 0 2}$ & $\mathbf{2 0 1 4}$ & & & $\mathbf{2 0 0 2}$ & $\mathbf{2 0 1 4}$ & \\
\hline AL & -0.0473058 & -0.0601038 & $-27,0$ & PB & -4.21233 & -3.675 & 13,0 \\
AM & 2.94708 & -0.21531 & 74,0 & PE & -5.31105 & -4.62319 & 13,0 \\
AP & -2.42591 & -0.804923 & 67,0 & PR & -9.31496 & -8.16064 & 12,0 \\
BA & -7.50348 & -26.5915 & $-254,0$ & RJ & 1.82397 & 15.6277 & 757,0 \\
CE & -15.7378 & -12.8372 & 18,0 & RN & -7.48394 & -7.64192 & $-2,0$ \\
DF & -0.0523723 & -0.532367 & $-917,0$ & RO & -0.427758 & -5.24487 & $-1.126,0$ \\
ES & -2.86537 & -4.96016 & $-73,0$ & RR & -0.0302475 & -0.475011 & $-1.470,0$ \\
GO & -7.43675 & -7.32813 & 1,0 & RS & -13.6121 & -0.0258735 & 100,0 \\
MA & -0.742633 & -1.42076 & $-91,0$ & SC & -23.6627 & -13.334 & 44,0 \\
MG & -4.40659 & -8.64094 & $-96,0$ & SE & -0.466924 & -0.0934123 & 80,0 \\
MS & -1.79965 & -4.09568 & $-128,0$ & SP & 142.41 & 124.439 & $-13,0$ \\
MT & -3.45032 & -9.95054 & $-188,0$ & TO & -0.021125 & -2.37479 & $-1.1142,0$ \\
PA & -13.6135 & -21.8597 & $-61,0$ & & & & \\
\hline
\end{tabular}

Fonte: Dataviva.info. Elaboração dos autores.

O Quadro 1 apresenta a posição dos estados brasileiros no ranking de complexidade econômica no período de 2002 a 2014, sendo o $1^{\circ}$ lugar associado ao maior valor deste índice (ECI). A primeira posição é ocupada pelo estado de São Paulo que, embora tenha registrado perda de complexidade entre 2002 e 2014, alcançou ECI oito vezes maior que o Rio de Janeiro, segundo estado de maior complexidade econômica do país. 
QUADRO 1

Ranking no índice de complexidade econômica Estados brasileiros - 2002-2014

\begin{tabular}{|c|c|c|c|c|c|c|c|c|c|c|c|c|c|}
\hline $\begin{array}{c}\text { Posição no } \\
\text { Ranking }\end{array}$ & 2002 & 2003 & 2004 & 2005 & 2006 & 2007 & 2008 & 2009 & 2010 & 2011 & 2012 & 2013 & 2014 \\
\hline 1 & $\mathrm{SP}$ & SP & SP & SP & SP & SP & $\mathrm{SP}$ & $\mathrm{SP}$ & SP & SP & SP & $\mathrm{SP}$ & SP \\
\hline 2 & AM & $\mathrm{AM}$ & RJ & AM & AM & RJ & AM & RJ & $\mathrm{AM}$ & $\mathrm{RJ}$ & RJ & RJ & RJ \\
\hline 3 & $-\frac{\mathrm{RJ}}{\mathrm{n}}$ & $\mathrm{RJ}$ & AM & RJ. & R & AM & RJ. & AM & $\mathrm{RJ}$ & AM & AM & AM & AM \\
\hline 4 & $\overline{T O}$ & TÓ & $\mathrm{DF}$ & $\overline{A C}$ & $\overline{A C}$ & $A C$ & $\overline{\mathrm{DF}}$ & $\overline{R R}$ & PR & $\mathrm{DF}$ & $\overrightarrow{\mathrm{DF}}$ & $\overline{D F}$ & RS \\
\hline 5 & RR & $A C$ & RR & RR & DF & AL & RR & AC & AC & AL & $A C$ & SE & AC \\
\hline 6 & $A C$ & DF & TO & DF & TO & MA & $A C$ & DF & MA & MA & RR & AC & SE \\
\hline 7 & DF & $R R$ & $A C$ & то & RR & DF & Tо & SE & RR & $A C$ & SE & AL & AL \\
\hline 8 & RO & RO & SE & PI & SE & RR & MA & то & DF & RR & AL & RR & RR \\
\hline 9 & SE & SE & AL & SE & PI & SE & SE & PR & SE & SE & MA & AP & DF \\
\hline 10 & MA & AP & $\mathrm{MA}$ & MS & MA & PI & PI & PI & то & TO & то & MA & AP \\
\hline 11 & $\mathrm{AL}$ & AL & PI & MA & MS & TO & AL & MA & AL & PI & PI & TO & MA \\
\hline 12 & MS & MA & AP & AP & AL & RO & RO & AL & PI & PB & AP & PI & PI \\
\hline 13 & AP & PI & MS & RO & Ro & AP & MS & AP & RO & RO & PR & MS & то \\
\hline 14 & PI & MS & RO & AL & AP & MS & PB & ES & AP & AP & RS & PE & PB \\
\hline 15 & ES & ES & MT & RS & ES & PR & AP & PB & ES & $\mathrm{PE}$ & PB & PB & MS \\
\hline 16 & MT & PB & ES & GO & $P R$ & PB & $P R$ & RO & PB & ES & RO & ES & $\mathrm{PE}$ \\
\hline 17 & PB & GO & PB & PE & PB & ES & PE & PE & $\mathrm{PE}$ & MS & ES & Ro & ES \\
\hline 18 & MG & $\mathrm{PE}$ & RS & PB & MG & PE & ES & MS & MS & GO & MS & GO & Ro \\
\hline 19 & $\mathrm{PE}$ & $\mathrm{RN}$ & $\mathrm{PE}$ & ES & MT & MG & $\mathrm{RN}$ & $\mathrm{RN}$ & MT & RN & $\mathrm{PE}$ & $\mathrm{RN}$ & GO \\
\hline 20 & GO & MT & GO & $\mathrm{RN}$ & GO & GO & RS & GO & RS & MT & MG & RS & $\mathrm{RN}$ \\
\hline 21 & $\mathrm{RN}$ & $P R$ & $\mathrm{RN}$ & MT & PE & MT & GO & RS & RN & PR & $\mathrm{RN}$ & PR & PR \\
\hline 22 & BA & RS & $P R$ & $P R$ & $\mathrm{RN}$ & $\mathrm{RN}$ & SC & MG & GO & RS & GO & MT & MG \\
\hline 23 & PR & BA & MG & PA & CE & SC & MG & MT & $B A$ & MG & MT & CE & MT \\
\hline 24 & RS & MG & BA & MG & BA & RS & MT & SC & MG & SC & CE & SC & $\mathrm{CE}$ \\
\hline 25 & $\mathrm{PA}$ & $\mathrm{PA}$ & $\mathrm{CE}$ & $\mathrm{CE}$ & RS & $\mathrm{CE}$ & CE & CE & SC & $\mathrm{CE}$ & SC & $B A$ & SC \\
\hline 26 & CE & $\mathrm{CE}$ & PA & BA & SC & BA & BA & $B A$ & CE & BA & BA & MG & PA \\
\hline 27 & SC & $\mathrm{SC}$ & $\mathrm{SC}$ & SC & $\mathrm{PA}$ & PA & PA & PA & PA & PA & PA & PA & $\mathrm{BA}$ \\
\hline
\end{tabular}

Fonte: Dataviva.info. Elaboração dos autores.

Observa-se que, de modo geral, os estados mantiveram suas posições relativas estáveis no ranking. Como o processo de formação de novas capacidades tende a ser lento e gradual, é esperado que a mudança de posição no ranking também seja gradativa. No entanto, observam-se casos nos quais ocorreram mudanças bruscas na posição do ranking, de um ano para o outro. Por exemplo, o Paraná caiu do quarto lugar, em 2010, para o vigésimo, em 2011, enquanto o Rio Grande do Sul saiu da nonagésima posição, em 2013, para o quarto colocado, em 2014. Mudanças fortes e rápidas podem indicar a dificuldade desses estados em conseguirem consolidar a exportação de produtos com maior complexidade no mercado internacional. $\mathrm{Ou}$ 
seja, nos anos em que esses produtos são exportados com VCR > 1, há uma melhoria significativa do indicador de complexidade econômica do estado que o exportou. Essa dinâmica é indicativa não somente da volatilidade da demanda internacional, mas também da competição existente entre os próprios estados brasileiros na consolidação de seus produtos no mercado internacional.

Chama a atenção o contraste registrado entre a posição relativamente confortável do Amazonas e a classificação desfavorável de Minas Gerais no ranking de complexidade econômica. Esse contraste está associado, principalmente, à base econômica regional que, no caso de Minas Gerais, apoia-se na exportação de commodities minerais e agrícolas (produtos pouco complexos, sob o ponto de vista da incorporação de conhecimento); no caso do Amazonas, reflete as vendas externas de produtos relativamente mais complexos, associados ao polo eletrônico da Zona Franca de Manaus. ${ }^{9}$

A baixa performance na complexidade econômica de Minas Gerais é acompanhada pelo baixo crescimento econômico. Entre 2010 e 2014, Minas Gerais obteve o pior desempenho na variação do PIB real entre os estados brasileiros, registrando crescimento acumulado de 5,6\% (IBGE, 2016). Cabe ressaltar que a participação do PIB do estado de Minas Gerais no total nacional corresponde a $8,9 \%,{ }^{10}$ posicionando-o como a terceira maior economia do país (FJP, 2016). O estado também ocupa lugar de destaque nas exportaçóes brasileiras, respondendo por $11,8 \%$ do total exportado. ${ }^{11}$ No entanto, o tamanho da economia mineira não guarda relação com o seu nível atual de sofisticação econômica, dado o padrão de especialização da sua pauta exportadora: os dois principais produtos com vantagem comparativa revelada - minério de ferro e café - respondem por mais de $50 \%$ do valor exportado.

A Tabela 4 apresenta os dez produtos com vantagem comparativa revelada que obtiveram maior participação na pauta de exportação de Minas Gerais em 2014.

9 As medidas de política industrial e de comércio exterior, ao promoverem a consolidação da Zona Franca de Manaus - criada em 1967 -, certamente desempenharam papel relevante para a ampliação das capacidades produtivas da economia local, assentada, principalmente, nos segmentos extrativo-vegetal e silvicultura.

10 Considerando o Produto Interno Bruto (PIB) nominal referente a 2014.

11 Disponível em: <http://www.mdic.gov.br/comercio-exterior/estatisticas-de-comercio-exterior/comex-vis/frame-uf-produto?uf=mg>. 
TABELA 4

Dez produtos (VCR >1) com maior participação na pauta de exportação Estado de Minas Gerais - 2014

\begin{tabular}{|c|c|c|c|c|c|}
\hline $\begin{array}{l}\text { Código } \\
\text { HS }\end{array}$ & Produto & Classificação Lall & PCI & $\begin{array}{c}\text { Valor exportado } \\
\text { (em milhôes } \\
\text { US\$) }\end{array}$ & $\begin{array}{l}\text { Participa- } \\
\text { ção nas } \\
\text { Exporta- } \\
\text { çóes (\%) }\end{array}$ \\
\hline 52601 & $\begin{array}{l}\text { Minério de } \\
\text { Ferro }\end{array}$ & $\begin{array}{l}\text { Produto baseado em } \\
\text { recurso de outra fonte }\end{array}$ & -1.79 & $12,232.10$ & 40,93 \\
\hline 20901 & Café & Produtos primários & -2.25 & $4,114.83$ & 13,98 \\
\hline 157202 & Ferro-ligas & $\begin{array}{l}\text { Manufatura de média } \\
\text { tecnologia }\end{array}$ & -0.72 & $1,735.26$ & 5,80 \\
\hline 147108 & Ouro & - & -2.12 & $1,294.27$ & 4,43 \\
\hline 41701 & $\begin{array}{l}\text { Açúcar in } \\
\text { natura }\end{array}$ & $\begin{array}{l}\text { Produto baseado em } \\
\text { recurso agrícola }\end{array}$ & -1.51 & 903.69 & 3,07 \\
\hline 157304 & $\begin{array}{l}\text { Tubos de ferro } \\
\text { ou aço }\end{array}$ & $\begin{array}{l}\text { Manufatura de baixa } \\
\text { tecnologia }\end{array}$ & 0.61 & 731.60 & 2,49 \\
\hline 21201 & Soja & Produtos primários & -0.42 & 722.13 & 2,46 \\
\hline 104703 & $\begin{array}{l}\text { Pastas químicas } \\
\text { de madeira à } \\
\text { soda ou sulfato }\end{array}$ & $\begin{array}{l}\text { Produto baseado em } \\
\text { recurso agrícola }\end{array}$ & -0.09 & 569.41 & 1,94 \\
\hline 157201 & Ferro fundido & $\begin{array}{l}\text { Manufatura de média } \\
\text { tecnologia }\end{array}$ & -0.88 & 394.44 & 1,33 \\
\hline 157207 & $\begin{array}{l}\text { Produtos semi- } \\
\text { manufaturados } \\
\text { de ferro }\end{array}$ & $\begin{array}{l}\text { Manufatura de média } \\
\text { tecnologia }\end{array}$ & -0.67 & 383.43 & 1,30 \\
\hline
\end{tabular}

Fonte: Dataviva.info. Elaboração dos autores.

Nesse contexto, uma análise adicional faz-se necessária: observar o comportamento dos produtos ainda não exportados com vantagem comparativa revelada. $\mathrm{O}$ indicador de prognóstico de complexidade (COI) permite mensurar a perspectiva futura de complexidade econômica de determinada região, dado o grau de complexidade e proximidade entre os produtos que ainda não possuem VCR e a cesta de produtos exportados com vantagem comparativa. Segundo Hausmann, Espinoza e Santos (2015), uma região com baixa complexidade econômica (ECI), mas que apresente alto prognóstico de complexidade (COI), estaria em melhores condições para avançar na transformação da sua base produtiva em comparação com uma região que já possua alta complexidade. 
O Gráfico 1 compara os estados brasileiros a partir dos indicadores de complexidade (ECI) e de prognóstico de complexidade (COI), sendo o tamanho das siglas proporcional ao PIB nominal dos estados. Aqueles que apresentaram os maiores valores para o COI, em 2014, foram Santa Catarina, Rio Grande do Sul, Rio de Janeiro, Amazonas e Paraná. Esses resultados permitem dizer que a atual estrutura econômica desses estados encontra-se relativamente próxima de produtos complexos, quando comparada aos demais estados brasileiros. Para esses estados, o processo de sofisticação seria, portanto, relativamente mais fácil. Em contraste, aqueles que registraram indicadores de baixa complexidade econômica e baixo prognóstico de complexidade não somente possuem uma estrutura econômica pouco complexa, como também se encontram distantes de produtos sofisticados. Nesses casos, o desenvolvimento de capacidades produtivas mais sofisticadas requer volumosos investimentos.

\section{GRÁFICO 1}

Prognóstico de complexidade econômica

Estados brasileiros - 2014

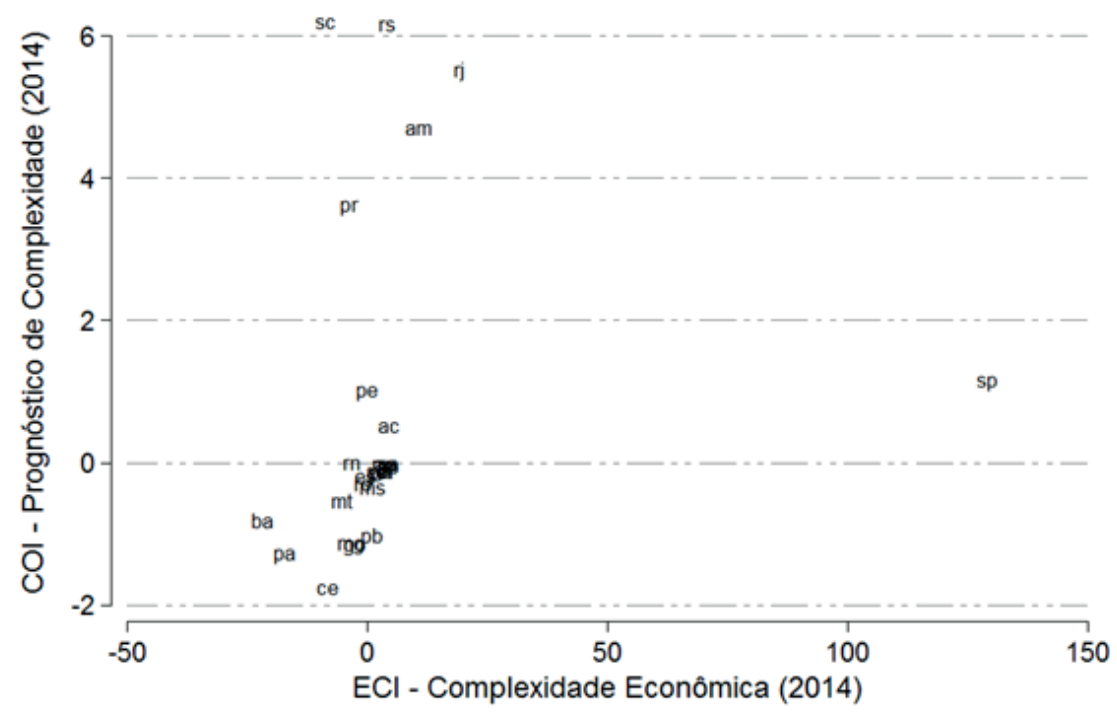

Fonte: Dataviva.info. Elaboração dos autores.

Ainda no que diz respeito ao indicador de prognóstico de complexidade, conforme mostrado no Gráfico 1, o desempenho mineiro, em 2014, também não foi favorável, haja vista que o estado obteve o quarto pior resultado de prognóstico 
de complexidade entre os estados brasileiros. O indicador de prognóstico de Minas Gerais afasta-se significativamente dos demais estados que possuem níveis próximos de PIB, tais como Rio de Janeiro, Paraná e Rio Grande do Sul. Nesse sentido, é preocupante o paradoxo enfrentado por Minas Gerais, terceiro maior estado brasileiro em termos de produção total, mas com estrutura produtiva pouco complexa e com baixas possibilidades de sofisticação futura.

\subsection{Minas Gerais e a armadilha da baixa complexidade econômica}

De modo geral, seguindo a tendência da economia brasileira, Minas Gerais apresentou crescimento econômico. Entre 2003 e 2008, impulsionado, dentre outros, pelo aumento das exportaçóes - principalmente, de produtos minerais, siderúrgicos e café - o PIB mineiro cresceu em média 5,04\% a.a. Em 2009 - ano em que os impactos negativos da crise financeira mundial iniciada no mercado norte-americano se fizeram sentir no Brasil -, o PIB de Minas Gerais sofreu retração de 4\% para, no ano seguinte (quando o conjunto da economia brasileira também já apresenta recuperação), registrar significativa taxa de aceleração de 8,9\%. Em 2011, a taxa positiva foi de $2,8 \%$ e, desde então, ocorreu desaceleração do crescimento, com a taxa tendo alcançado 2,5\% em 2013 (FJP, 2013).

Do ponto de vista do comércio internacional, os resultados desse estudo apontam que, entre 2002 e 2007, período que antecede a crise financeira internacional, Minas Gerais vivenciou um processo de expansão de sua cesta de produtos com vantagem comparativa, movimento esse que se inverteu a partir de 2008, quando a pauta de exportação tornou-se ainda mais concentrada (Gráfico 2).

Conforme analisado na seção anterior, a concentração da cesta de exportações ao longo do período 2002-2014 não foi um processo vivenciado apenas por Minas Gerais, mas por todos os estados reconhecidamente produtores de commodities, principalmente recursos minerais. Porém, o problema mais grave do comércio exterior de Minas Gerais é que a perda de vantagens comparativas ao longo do período analisado, especialmente após a crise internacional, se deu em produtos com complexidade relativamente mais elevada. O Gráfico 3 apresenta a evolução do valor médio de complexidade dos produtos exportados com vantagem comparativa durante o período estudado. Observa-se que, entre 2002 e 2005, o ganho de vantagem comparativa se deu em produtos pouco complexos, uma vez que se observou diminuição da complexidade média dos produtos. Já entre 2005 e 2008, Minas Gerais volta a exportar produtos mais complexos, contribuindo para o au- 
mento da complexidade média, mas, a partir de 2009, o estado não somente perde vantagem comparativa, aumentando a concentração da cesta, como também deixa de exportar produtos relativamente mais complexos. Em 2014, a complexidade média dos produtos mineiros exportados com vantagem comparativa foi a menor observada na série histórica.

\section{GRÁFICO 2}

Evolução da cesta de produtos com vantagem comparativa

Estado de Minas Gerais - 2002-2014

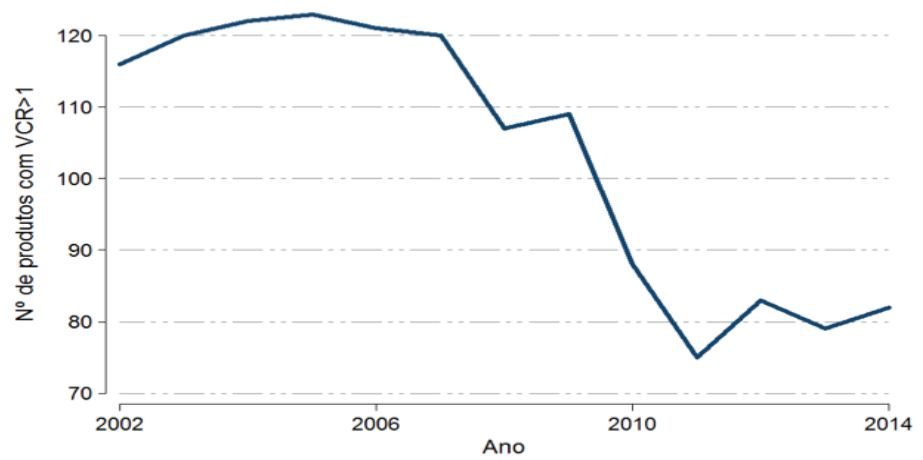

Fonte: Ministério da Indústria, Comércio Exterior e Serviços. Secretaria de Comércio Exterior (MDIC/Secex). Elaboração dos autores.

GRÁFICO 3

Evolução da complexidade dos produtos com VCR

Estado de Minas Gerais - 2002-2014

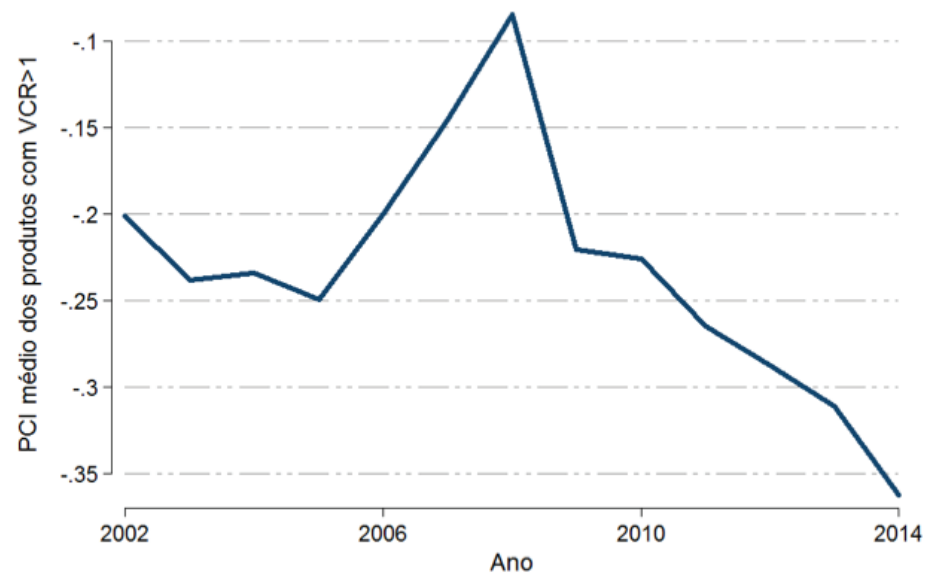

Fonte: Dataviva.info. Elaboração dos autores. 
A perda de vantagem comparativa associada à perda de produtos complexos afeta diretamente a evolução do product space de Minas Gerais durante o período, o que é ilustrado na Figura 1, elaborada com base na plataforma Dataviva, considerando-se os anos 2002, 2007 e 2014. Ela retrata os produtos que Minas Gerais exportou com vantagem comparativa no ano específico (cada ponto colorido representa um setor econômico) e a rede de produtos (pontos e traços em cinza claro). Enquanto a rede de produtos tem seu formato definido pelas probabilidades de coexportação de um mesmo produto pelos países - independentemente dos valores exportados por Minas Gerais -, os pontos destacados representam especificamente as conexões existentes entre os produtos exportados por Minas Gerais com vantagem comparativa revelada.

Entre 2002 e 2007, observa-se que o product space de Minas Gerais "caminhou" ligeiramente para o centro, uma vez que o segmento de produtos relativo a máquinas e equipamentos de transporte - mostrados nas cores azul claro e azul escuro - passaram a ser exportados com vantagem comparativa e, portanto, ganharam representatividade no centro do product space (Figura 1). Já entre 2007 e 2014, alguns grupos de produtos deixaram de figurar no product space de Minas Gerais. Em primeiro lugar, registra-se diminuição dos produtos relativos ao grupo máquinas e equipamentos de transporte. Em segundo lugar, o segmento relativo a artigos têxteis deixa de ser exportado com vantagem comparativa. Outro grupo que perde força é o de gênero alimentício; e, finalmente, também se registra diminuição do segmento de produtos químicos.

\section{FIGURA 1}

Product space, segundo setor

Estado de Minas Gerais - 2002-2014

2002

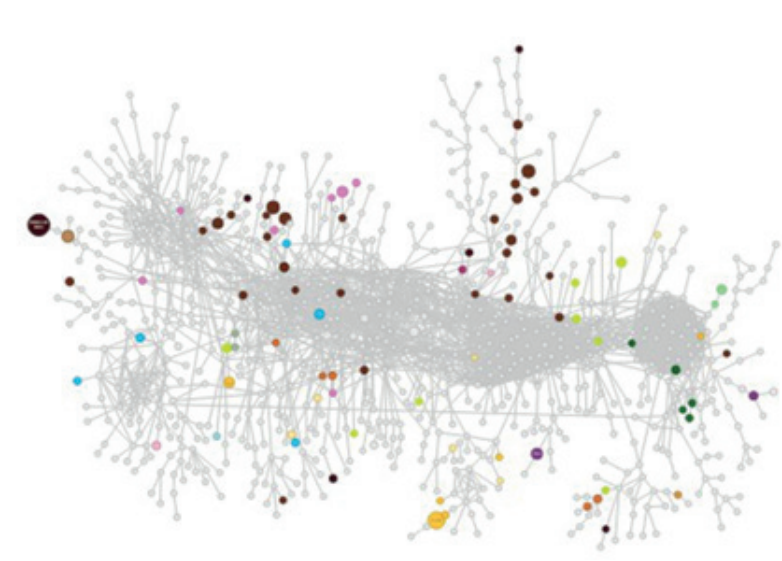




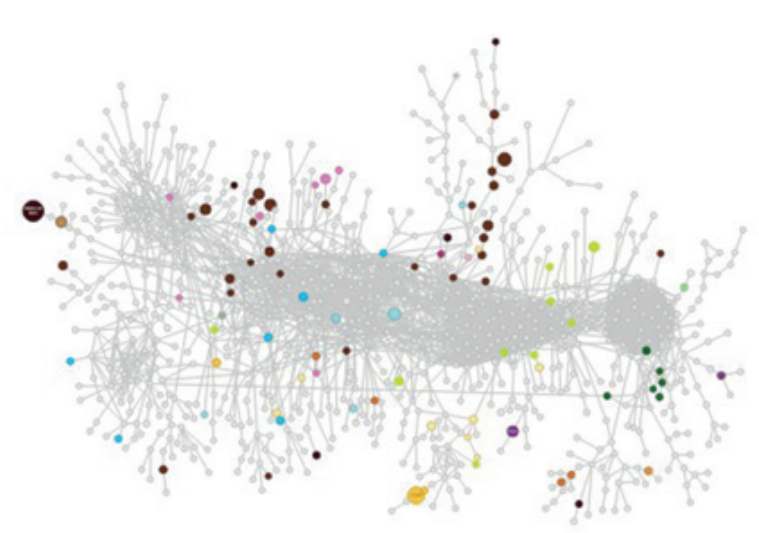

2014

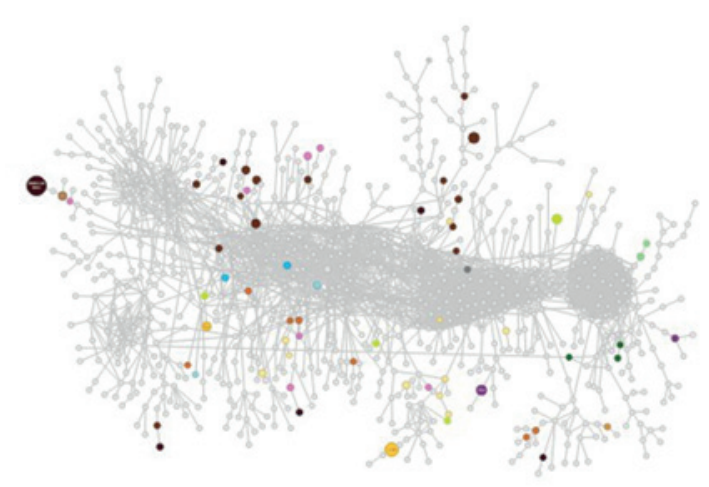

Fonte: Plataforma Dataviva.

Outra forma de analisar a trajetória do product space de Minas Gerais é observar a evolução das distâncias médias dos produtos ao longo do tempo. A distância média agrega as distâncias de todos os produtos exportados por uma dada localidade em relação aos produtos em que essa localidade possui vantagem comparativa revelada. Quanto maior for a distância média, mais disperso tende a ser o product space e, consequentemente, mais difícil a possibilidade de acúmulo e compartilhamento de conhecimento produtivo entre diferentes atividades econômicas.

Em Minas Gerais, a distância média dos produtos manteve-se na casa de 0,9 ao longo do período analisado, com gradual aumento a partir de 2008, conforme 
mostrado no Gráfico 4. Isso significa que os produtos que o estado não exporta com vantagem comparativa $(\mathrm{VCR}<1)$ encontram-se distantes dos produtos com vantagem comparativa (VCR $>1$ ), sendo que essa distância ampliou-se ainda mais a partir de 2008. Segundo Hausmann e Klinger (2007), a proximidade de um produto particular com áreas onde já existem vantagens comparativas é uma das variáveis mais significativas para determinar se um país irá desenvolver vantagem comparativa naquele produto no futuro. Nesse sentido, a localização atual de Minas Gerais no product space sinaliza poucas oportunidades para transformação de sua matriz produtiva.

\section{GRÁFICO 4}

Evolução das distâncias médias no product Space

Estado de Minas Gerais - 2002-2014

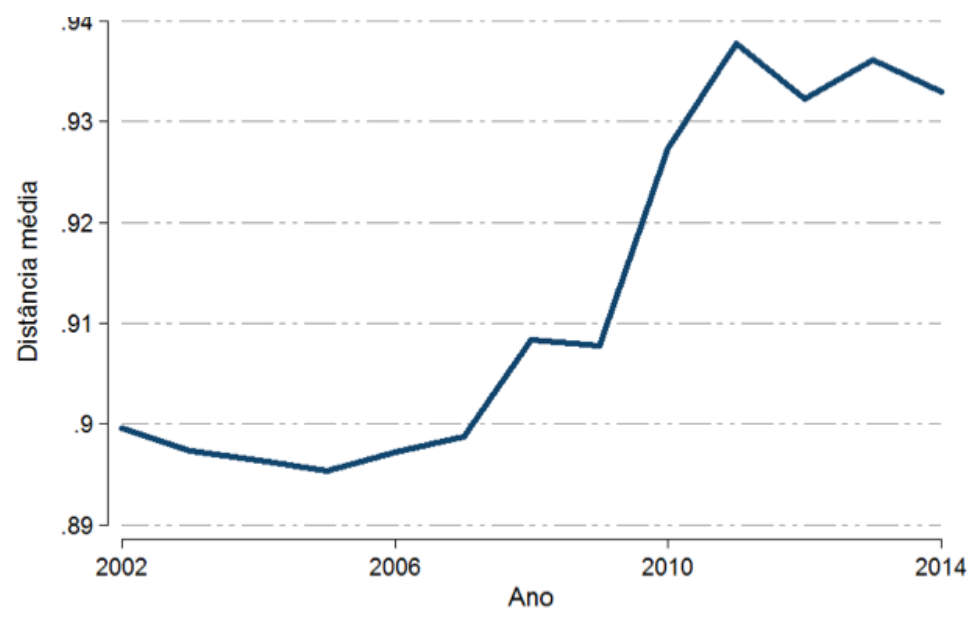

Fonte: Dataviva.info. Elaboração dos autores.

Por fim, o Gráfico 5 apresenta a distribuição dos produtos exportados por Minas Gerais, em 2014, a partir de suas medidas de complexidade e distância internacional. Observa-se que os produtos mais complexos da cesta de exportação mineira possuem os valores mais elevados de distância.

A configuração de um product space organicamente pouco conectado, com distâncias elevadas e vantagem comparativa em produtos pouco complexos, é um fator que contribui para que o indicador de complexidade econômica de Minas Gerais mantenha-se em patamares tão baixos. Para agravar esse quadro, na última década, o estado vivenciou uma trajetória de aumento de concentração da pauta exportadora associada à perda de competividade em produtos relativamente mais complexos. 


\section{GRÁFICO 5}

Complexidade e distância internacional dos produtos exportados

Estado de Minas Gerais - 2014

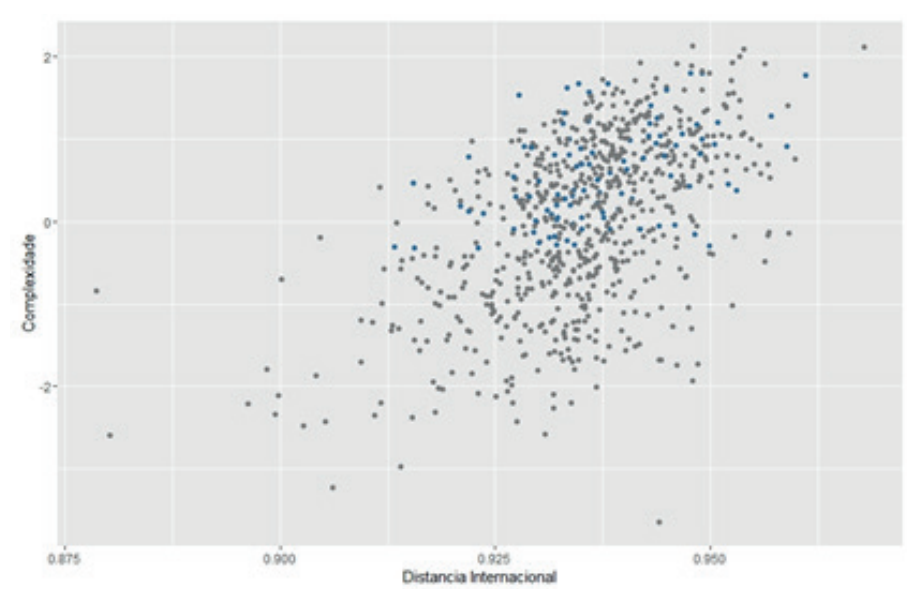

Fonte: Dataviva.info. Elaboração dos autores.

Assim, são fortes os indícios, revelados por esse estudo, de que a situação que Minas Gerais experimentou no período 2002-2014 corresponde ao que Hausmann e Hidalgo (2011) identificaram como a "armadilha da aquiescência": trata-se de um ciclo vicioso em que a baixa complexidade dificulta a capacidade de determinada região mover-se para produtos mais complexos, ampliando as distâncias e, consequentemente, a dificuldade para a sofisticação. No caso de Minas Gerais, o boom dos preços das commodities minerais teria agravado essa armadilha ao aumentar os incentivos para os investimentos no setor extrativista. Nesse sentido, a estrutura produtiva atual enfraquece as bases econômicas necessárias para o desenvolvimento das capacidades requeridas para a sofisticação futura.

\section{Conclusão}

Baseando-se na abordagem da complexidade econômica e nos indicadores disponíveis na plataforma Dataviva, o artigo analisou a trajetória recente de sofisticação econômica de Minas Gerais em relação aos demais estados brasileiros. A principal questão que norteou o artigo foi entender se o ciclo recente de aumento do preço das commodities poderia implicar a perda de complexidade da estrutura produtiva e, consequentemente, o comprometimento do desenvolvimento futuro de Minas Gerais, um dos efeitos relacionados à chamada "doença holandesa". Tal como no 
Atlas da complexidade econômica, indicadores de complexidade foram utilizados como proxy da disponibilidade de conhecimento embebido na estrutura produtiva dos estados. Não por acaso, observou-se relação positiva e significativa entre complexidade econômica e PIB per capita para o conjunto dos 27 estados brasileiros, corroborando a tese de que o ganho de complexidade está associado ao aumento da prosperidade econômica.

Ao comparar os estados brasileiros quanto ao grau de complexidade econômica e o tamanho de suas economias, constatou-se a singularidade do caso de Minas Gerais: terceira maior economia do país com um dos piores resultados em sofisticação econômica. Minas Gerais obteve desempenho ruim tanto nos indicadores de complexidade econômica atual quanto nos de prognóstico de complexidade futura, quadro agravado a partir de 2008, quando se observa tendência de concentração da cesta de exportação em produtos de baixa complexidade econômica. Ao mesmo tempo, verifica-se aumento das distâncias do product space acompanhado de sua "periferização", dificultando o processo de sofisticação econômica.

Esse quadro poderia ser atenuado se Minas Gerais estivesse apresentando taxas satisfatórias de crescimento econômico. Contudo, esse não é o caso. No período recente (2010-2014), Minas Gerais obteve o pior desempenho entre os estados brasileiros na variação acumulada do PIB real. Seguindo a análise de Hausmann et al. (2014), esse resultado sugere que Minas Gerais terá mais dificuldade do que os demais estados brasileiros, que possuem similar nível de renda, para sofisticar sua economia.

Diante disso, o principal argumento do artigo é de que o estado de Minas Gerais encontra-se preso em uma armadilha de baixa complexidade e o boom do preço dos recursos minerais teria contribuído para reforçar essa armadilha. Quanto mais a estrutura produtiva beneficiava-se dos ganhos oriundos da exportação, menores eram os incentivos para investimento em novas áreas. Assim, ao mesmo tempo que Minas Gerais vivenciava o boom de suas exportações em produtos de baixa complexidade econômica, suas oportunidades para sofisticação foram progressivamente reduzidas, alimentando o ciclo vicioso da baixa complexidade.

O fim do ciclo das commodities pode significar uma janela de oportunidade no sentido de incentivar a busca por diversificação econômica. No entanto, o desafio da economia mineira não é apenas diversificar-se, mas também tornar-se competitiva na produção de produtos mais complexos, que atualmente encontram-se distantes dos produtos em que Minas possui vantagem comparativa. O encurtamento dessas distâncias requer incentivos para que os agentes econômicos invistam em novas 
capacidades e, mais importante, desenvolvam formas criativas para conectá-las às capacidades existentes. Ademais, Minas Gerais enfrenta um desafio adicional: a competição com os demais estados brasileiros num contexto em que a fronteira tecnológica move-se a passos largos.

Por isso, o sucesso da sofisticação depende de uma estratégia que permita a formação de novas capacidades e o enfrentamento à competição com as regiões que já se encontram próximas ao centro do product space. A lição ensinada pela abordagem da complexidade aponta para a necessidade de políticas que priorizem atividades econômicas que, simultaneamente, estejam próximas da atual estrutura produtiva e contribuam para maior sofisticação. Essa priorização demanda um exercício, a ser levado a cabo tanto pelo setor público quanto pelo privado de "autodescoberta" das atuais potencialidades econômicas do estado, de diagnóstico dos principais gargalos e de definição de metas que tornem possível o ganho de vantagem comparativa em produtos mais complexos. Contudo, o processo de deslocamento para o centro do product space não é simples. Avançar no conhecimento das dificuldades inerentes a esse processo mostra-se o primeiro passo para a formulação de uma estratégia promissora.

\section{Referências bibliográficas}

BDMG - Banco de Desenvolvimento de Minas Gerais. Diagnóstico da economia mineira: diagnóstico. Belo Horizonte: BDMG, 1968.

Economia mineira 1989: diagnóstico e perspectivas. Belo Horizonte: BDMG, v. $1,1989$.

Minas Gerais do século XXI. Belo Horizonte: Rona Editora, 2002.

BRESSER-PEREIRA, L. C.; GALA, P. Macroeconomia estruturalista do desenvolvimento. Revista de Economia Política, v. 30, n. 4, p. 663-686, 2010.

BRESSER-PEREIRA, L. C. Reflecting on new developmentalism and classical developmentalism. Revista de Economia Política, v. 36, n. 2, p. 237-265, 2016.

CAMARGO, J.; GALA, P. The resource curse reloaded: revisiting the Dutch disease with economic complexity analysis. São Paulo: Fundação Getúlio Vargas, 2017 (Working Paper, n. 448).

CAMPOLINA, B.; CAVALCANTE, A. Economia minerária e seu impacto urbano: desafios e contradições na Região Metropolitana de Belo Horizonte. Redes - Santa Cruz do Sul: Universidade de Santa Cruz do Sul, v. 22, n. 1, janeiro-abril, 2017. 
CORDEN, W. M. Booming sector and Dutch disease economics: survey and consolidation. Oxford Economic Papers, v. 36, n. 3, p. 359-380, 1984.

FREITAS, E. E.; PAIVA, E. A. Diversificação e sofisticação das exportações: uma aplicação do product space aos dados do Brasil. Revista Econômica do Nordeste, v. 46, n. 3, p. 79-98, 2016. FJP - Fundação João Pinheiro. Perfil de Minas Gerais 2013. Belo Horizonte, 2013. Disponível em: < http://www.fjp.mg.gov.br/PerfildeMinasGerais2013.pdf>. Acesso em: 9 jan. 2016.

. Produto Interno Bruto de Minas Gerais. Relatório Anual de 2014. Disponível em: <http://www.fjp.mg.gov.br/index.php/docman/cei/pib/pib-anuais/664-monitor-fjp-relatorio-anual-do-pibmg-2014-completo/file>. Acesso em: 16 dez. 2016.

FURTADO, C. Desenvolvimento e subdesenvolvimento. Rio de Janeiro: Fundo de Cultura, 1961.

HARTMANN, D. et al. Linking economic complexity, institutions, and income inequality. World Development, v. 93, p. 75-93, 2017.

HAUSMANN, R.; HWANG, J.; RODRIK, D. What you export matters. Journal of Economic Growth, v. 12, p. 1-25, 2007.

HAUSMANN, R.; KLINGER, B. The structure of the product space and the evolution of comparative advantage. Cambridge, MA: Center for International Development, Harvard University, 2007 (CID Working Paper, n. 146).

HAUSMANN, R.; HIDALGO, C. A. The network structure of economic output. Journal of Economic Growth, v. 16, n. 4, p. 309-342, 2011.

HAUSMANN, Ricardo et al. The atlas of economic complexity: mapping paths to prosperity. Cambridge, MA: MIT Press, 2014.

HAUSMANN, R.; ESPINOZA, L.; SANTOS, M. A. Diagnostico de crecimiento de Chiapas: la trampa de la baja productividad. Cambridge, MA: Center for International Development, Harvard University, 2015 (CID Working Paper, n. 304).

HIDALGO, C. A. et al. The product space conditions the development of nations. Science, v. 317, n. 5837, p. 482-487, 2007.

HIDALGO, C. A.; HAUSMANN, R. The building blocks of economic complexity. Proceedings of the National Academy of Sciences, v. 106, n. 26, p. 10570-10575, 2009.

IBGE - Instituto Brasileiro de Geografia E Estatística. Contas Regionais do Brasil: 2010-2014. Rio de Janeiro: IBGE, 2016 (Contas Nacionais, n. 53). Disponível em: <http://biblioteca. ibge.gov.br/pt/biblioteca-catalogo?view=detalhes\&id=298881 >. Acesso em: 20 ago. 2017.

JANKOWSKA, A.; NAGENGAST, A.; PEREA, J. R. The middle-income trap: comparing Asian and Latin American experiences. OECD Development Centre Policy Insights, n. 96, 2012. 
KALDOR, N. Causes of the slow rate of economic growth of the United Kingdom. Cambridge: Cambridge University Press, 1966.

LALL, S. Technological capabilities and industrialization. World Development, v. 20, n. 2, p. 165-186, 1992.

MEDEIROS, C. Natural resources nationalism and development strategies. Circus, jun. 2012. Disponível em: <http://grupolujan-circus.blogspot.com.br/2012/06/natural-resourses-nationalism-and.html>. Acesso em: 14 jul. 2014.

MISSIO, F.; JAYME, F. OREIRO, J. L. The structuralist tradition in economics: methodological and macroeconomics aspects. Brazilian Journal of Political Economy, v. 35, n. 2, p. 247-266, 2015.

NU.CEPAL Naciones Unidas. Comisión Económica para América Latina y el Caribe. Recursos naturales: situación y tendencias para una agenda de desarrollo regional en América Latina y el Caribe. Cepal, 2013.

PALMA, G. Four sources of "de-industrialisation" and a new concept of the "Dutch disease". In: OCAMPO, J. A. (ed.). Beyond reforms: structural dynamics and macroeconomic vulnerability. New York: Stanford University Press and World Bank, 2005.

PREBISCH, R. O desenvolvimento econômico da América Latina e seus principais problemas. Revista Brasileira de Economia, v. 3, n. 3, p. 47-111, 1949.

RODRIK, D. The past, present, and future of economic growth. Global Citizen Foundation, June 2013a (Working Paper, n. 1). Disponível em: <http://www.gcf.ch/wp-content/uploads/2013/06/GCF_Rodrik-working-paper-1_-6.17.131.pdf>.

Structural change, Fundamentals, and Growth: an overview. 2013b (Working paper). Disponível em: <https://drodrik.scholar.harvard.edu/files/dani-rodrik/files/structural-change-fundamentals-and-growth-an-overview_revised.pdf>.

SACHS, J. D.; WARNER, A. M. Natural resource abundance and economic growth. National Bureau of Economic Research, 1995 (NBER Working Paper Series, n. 5398). 
